\title{
Teaching Tomorrow's Leaders by Discussing Today's Media
}

\author{
Lee Morin, M.A. \\ Leadership and Organizational Studies \\ University of Southern Maine \\ Elizabeth Fisher Turesky, Ph.D \\ Leadership and Organizational Studies \\ University of Southern Maine \\ Betty Robinson, Ph.D \\ Leadership and Organizational Studies \\ University of Southern Maine
}

\begin{abstract}
Can parents identify leadership lessons in children's media and use them to teach their children leadership? Thirty participants were asked to answer questions about leadership in children's media before and after watching clips of a popular G-rated children's movie. The results from the questionnaire indicated that parents do recognize leadership behaviors in children's media and do feel that their children are learning from the media. As a result of this learning environment, children become more aware of leadership. Further, sixty-seven percent of the parents claimed to reinforce the positive messages in the media, and seventy percent claimed to teach their children about leadership. In two participant groups, results varied by gender and education level. The study recommends ways for parents and media producers to emphasize leadership messages so as to foster leadership development in children.
\end{abstract}

\section{Introduction}

A parent's love: the most underutilized resource in education.

Experts agree that leadership behaviors are learned (Burngardt, 1997). We learn them throughout life, but perhaps the most in childhood - from five to ten (Nelson, 2010). Children absorb important messages from their environment: peers, family members, and children's media. With age-appropriate content, children's television and movies can constructively influence a child's development. By understanding and reinforcing these messages, parents can help their children learn about leadership.

This research seeks to answer the following questions: Can the media teach children leadership? If so, how can parents reinforce these lessons? Since children's cognitive abilities are still developing, it is important to determine which leadership lessons children comprehend and can transfer into their day-to-day activities. Does parental co-viewing add value to the experience of the program? If so, how should a parent reinforce embedded leadership messages? Lastly, do parents know enough about leadership to reinforce these lessons in their children's lives? 
Any parent knows that becoming a good citizen or leader poses a formidable challenge. A parent with such hopes should seize teachable leadership moments in their children's lives, including mediated experiences. Media can support social lessons, and parents should carefully choose programs that teach leadership. Producers of children's media should take note of this line of thinking. If parents purchase programs that reinforce leadership, then producers may focus more on it. In fact, producers may incorporate co-viewing aspects into their products, such as scheduling program time for parents to discuss the broadcast with their children.

\section{Literature Review}

Can parents watching children's programming with their children identify and then reinforce leadership lessons? This literature review examines four areas: (1) leadership as it pertains to this research, (2) children's inclination to learn about leadership, (3) children's inclination to learn about leadership from the media, and (4) the significance of media and parents' co-viewing.

Leadership Defined. From a great number of theories, we choose Stogdil's (1948) definition of leadership from his seminal publication on Leadership of children and young adults: working with others to achieve a goal (p.64). Kouzes \& Posner (2002) wrote, "Leadership is an observable set of skills and abilities that are useful ... and any skill can be strengthened, honed, and enhanced given the motivation and desire, the practice and feedback, and the role models and coaching" (p. 388). This research followed Stogdil's (1948) use of 'behavior,' 'skill,' 'attribute,' 'trait,' and 'lesson' to refer to general characteristics, capacities, motives, and patterns of leadership behavior, including ambition, motivation, integrity, confidence, empathy, creativity, and so on. The following section further discusses these features.

Leading means more than simply acquiring attributes. Stogdil (1948) noted, "Leadership is not a matter of passive status, or of the mere possession of some combination of traits. It appears rather to be a working relationship among members of a group, in which the leader acquires status through active participation and demonstration of his capacity for carrying cooperative tasks through and to completion" (p. 66). Kirkpatrick \& Locke (1991) further specified, "Traits alone... are not sufficient for successful business leadership -they are only a precondition. Leaders who possess the requisite traits must take certain actions to be successful" (p. 49). Which traits should child leaders have? Which behaviors should they learn?

Learning and developing leadership behaviors. Children receive educational and social messages from the media, but at what age and to what degree can they understand complex lessons of leadership? Nelson (2010) asserted that children begin displaying leadership from their fifth to their tenth years. They already have cognitive skills to learn leadership skills such as team building, problem solving, and conflict resolution (Nelson, 2010). This age range may seem wide, but considering the variables of how children learn, researchers accept a fiveyear span when most children learn leadership. According to McMahon (2004) a complex environment makes teaching leadership challenging, but clear objectives with specific outcomes make for effective teaching. McMahon (2004) also noted that learning must emphasize generalization or transfer of the skill to new situations, or it will have little value. Brungardt (1997) stated that realizing one's leadership potential requires both formal and informal learning 
activities. McMahon (2004) reported that "early experiences in life such as the ability to understand and deal with others, need for achievement, confidence, assertiveness and reliability impact adult leadership potential (p. 67)."

Social skills parallel leadership skills; many researchers consider them identical. Nelson's (2010) research showed that children can understand and exercise these aspects of leadership: integrity, responsibility, commitment, confidence, optimism, communication, vision, strategy, and dealing with change. Mawson's (2008) study of leadership in children's collaborative play found consistent actions among leaders in groups who were "leading the roles in play, supporting emotional well-being among the participants, including others in play/sharing, and conflict resolution" (p. 115). Through extensive investigation on social and leadership skills, Mawson's research has identified fourteen behaviors for parents to teach their children: integrity and honesty, confidence and charisma, problem solving and creative thinking, active listening, teamwork, effective communication, planning and vision, compromise, and self-motivation and passion. These important attributes require further discussion.

Integrity and honesty focus on telling the truth, self-respect, and respect for others. Riggio (2011) considered it vital to be straightforward and adhere to one's values. Confidence and charisma speak to having courage and trying new things. Andrews (2012) argued that to become confident leaders children must be assertive and "believe in themselves." Children should understand problem solving, creative thinking, and the importance of reaching an answer despite seeing several ways to get there (Swan, 2011). Children should learn to listen, which includes reflecting on what is being said. To ensure understanding, children should learn to repeat what is said to them (Swan, 2011). Children should appreciate teamwork, leading or following. They must learn to share ideas and to dare to lean on other work group members who fall behind (K.M., 2011). In theory, effective communication is perhaps the most complex of all the behaviors. K.M. (2011) wrote that children must communicate clearly so that others may follow. Planning (vision) is a crucial aspect of leadership. Without setting goals and visualizing next steps, implementing problem-solving strategies can be difficult (Loh, 2012). Compromising is critical when working in groups and solving problems. Children should learn to discuss issues thoroughly so as to address all parties' needs and to ensure progress (Loh, 2012). Lastly and perhaps with difficulty, children should be self-motivated and passionate in any activity (Loh, 2012).

The leadership elements of integrity and honesty, confidence and charisma, problem solving and creative thinking, active listening, teamwork, effective communication, planning and vision, compromise, and self-motivation and passion are vital for young children to learn to become leaders. The next section will discuss whether children can learn them from the media.

Children learning from the media. Research has resoundingly proven that children are learning from the media, here defined/limited as children's television and movies (Gaunlett, 1995; Davies, 1997). Many questions about the media pertain to their effect. What does a child take from television and movies and transfer to other aspects of life? McMahon (2004) affirmed that programs can teach if done thoughtfully. Media can make new, complex concepts meaningful to children. Walling (1976) asserted that media influences young viewers because their perceptions and personalities have not fully developed. Feshbach \& Feshbach (1997) 
reported empirical evidence that media viewing can enhance certain cognitive competencies, stimulate social behaviors, and evoke a range of emotional reactions (p. 6). Unfortunately not all of these social behaviors and emotional reactions are positive.

Many researchers criticize the effects of media on children. Wartella \& Robb (2008) claimed that watching programming can lead to attention development issues, behavioral challenges, and delayed emotional development because the child spends less time interacting with people and more time disconnected from the real environment (Calvert \& Wilson, 2008, p.18). A study by Friedrich \& Stein (1973) showed that children who watched programs containing inappropriate violence, language, or content displayed decreased self-regulation while kids who watched appropriate programs showed high levels of obedience and other positive social skills. Kirkorian, Wartella, \& Anderson (2008) indicated that children from lower-income homes had a tendency to consume more media and scored lower on academic measures than children from higher-income homes. Presumably, lower-income parents' not screening their children's entertainment selections detracted from their development. Ultimately, with either appropriate or inappropriate content or adequate or inadequate screening, the child's attitude towards the program (interest, engagement, attention) determined the program's influence (Walling, 1976).

Numerous studies show the usefulness of programming with age appropriate content for teaching engaged children. Children learn from media when they can stay attentive during the program, comprehend its content, and watch it again. Intelligence, gender, socioeconomic status, and age also affect learning (Kirkorian et al., 2008). Kirkorian et al. (2008) also reported that children under age two learn little from the media; experiments have repeatedly shown that they learn better from real-life experiences. However, by age three, children are active media users, able to imitate behaviors seen in programs. Educational programs with intentionally designed curricula in mathematics, science, and social skills have positive effects both short-term and long-term.

Research has shown that children can learn social skills informally, indirectly, or incidentally over time (Walling, 1976). These leadership behaviors are perhaps the most important skills children can learn from the media. Gaunlett (1995) claimed that the social effect of media has a positive influence on behavior such as "increases in altruism, helpfulness, generosity, empathy, and other social skills" (p. 45). Calvert \& Kotler (2003) noted that children often stated that they enjoy and learn from social programming. Friedrich \& Stein (1973) found more creativity and positive attitudes towards learning in kids who viewed educational programs early in their development than in kids who did not. Social content in media also fostered positive behaviors. Crane \& Chen (2003) found that there were more social programs for kids two to ten than for any other demographic, and that many children watched social programs such as Clifford, Arnold, Sesame Street, Bob the Builder, and Barney and Friends.

By understanding social influences in the media, young children learn to identify emotions and comprehend emotional situations. Children as young as four start to understand the mental state of others: they develop a 'theory of mind,' an important social skill that helps them coordinate relationships with others (Mar, Tackett, \& Moore, 2010). Although little empirical research has investigated the media's influence on the development of theory of mind, discussing 
the mental states (desires, beliefs, and emotions) of story characters with parents can help children develop one. Simulating the story experience may also engage theory of mind processes (Mar et al., 2010).

Another important aspect of the child/media relationship, transfer of learning (applying lessons from one situation to another), increases with age and repeated viewing of a program. Research suggests that children as young as three can transfer learning from educational programs to life situations. A paucity of research notwithstanding, repeating educational and social messages within different contexts and using different examples maximize transfer of learning (Kirkorian et al. 2008).

Additionally, ensuring children's learning from the media requires adult reinforcement with prosocial, theory of mind, and the transfer of learning exercises (Kirkorian et al., 2008). Ultimately the child must be engaged with the media to learn from them. Walling's (1976) study asked children if they learn from television. Seventy percent said "yes;" only thirty percent said "no" (p. 20). When asked to recall something that they had recently learned from television, forty five percent cited a specific example (p.20). So children learn from the media, but adult screening and reinforcement of the media messages determine if children apply what they learn elsewhere (Kirkorian et al., 2008).

Mediation and co-viewing. Parents stay abreast of what their children see by screening and co-viewing. These distinct actions together enable adults to monitor and to add value to the programs their children view. Bryce \& Leichter (1983) define mediation as "those processes by which family (or other institutions) filters educational influences. The process, by which it screens, interprets, criticizes, reinforces, complements, counteracts, refracts, and transforms" (p. 309). Dorr, Kovaric, \& Doubleday (1989) emphasizes that "with mediation parents can be certain what children are watching, help them understand the content, gain first-hand knowledge of the children's reaction to the content, encourage them to accept only messages parents endorse, and intervene immediately should there be undesirable content." (p. 35)

For co-viewing to be a learning experience, adults must interact and mediate with the child during the program. Walling (1976) and Bryce \& Leichter (1983) concur that learning is enhanced greatly when parents and children talk about what they are watching. This interaction can increase incidental learning and foster cognitive development.

Despite the constructive effects of mediation and co-viewing, questions remain concerning their degree and meaning. For Walling (1976) most television viewing takes place in the home, where parental influence is optimal; , and Alexander (2009) reported that children from eight to eighteen watch with their parents over fifty percent of the time. Contrary research reported families' watching television together but not interacting around the program (Calvert \& Wilson, 2008). For Wartella \& Robb (2008) co-viewing may mean that parents and children like the same programs, or that some family members have to watch what others are watching. Wartella \& Robb found that co-viewing increases as the children age and share interests with their parents. Alexander (2009) and Dorr et al. (1989) posited that co-viewing decreases in houses with several television sets, and the U.S. Census Bureau (2006) reported on average 2.4 televisions per household (in Calvert \& Wilson, 2008). Although there is no evidence suggesting 
a negative link between co-viewing or mediation with children's learning from media, "some studies fail to find a benefit" (Kirkorian et al., 2008, p.52).

Researchers agree upon the importance of thoughtful adult/child interaction during the program, e.g., answering questions, drawing attention to important aspects, and extending lessons presented (Kirkorian et al., 2008). In 1998 Valkenburg, Krcmar, \& de Roos looked for differences between neutral, passive and active, mediated co-viewing. Children who watched a program with an active parent scored significantly higher than those who did not, on subsequent comprehension tests (Kirkorian et al., 2008). In 1973 Friedrich \& Stein had found that children who watched Mister Rogers' Neighborhood with an active co-viewer and then talked about it increased their knowledge of its social message, which they could then apply elsewhere. Simply having co-viewing adults make inferences about a program can compensate for children's lower levels of cognition (Bryce \& Leichter, 1983).

Which side has the clearer picture? Ultimately, domestic differences determine effective co-viewing and mediation. Bryce \& Leichter (1983) wrote, "the home environment and how a family is organized will affect who watches, with whom, what is watched and when" (p. 309). Parents who believe that children can learn from media tend to co-view and incorporate media in the child's daily learning (Dorr et al., 1989). Mindful engagement and age-appropriate mediation associated with co-viewing can reinforce leadership messages.

To learn leadership (working with others to achieve a goal) children must participate in both formal and informal learning activities and learn social and leadership behaviors. Engaged children can learn them from the media if the content is age-appropriate. They learn best when parents co-view and reinforce lessons in the programs. Such dialogue helps children transfer these lessons to other aspects of their lives. No existing literature directly pertains to leadership development in children's media; hence this research is warranted.

\section{Methodology}

Method. This research is exploratory analysis for grounded theory (Leedy \& Ormrod, 2013). In grounded theory, a qualitative technique, instead of applying existing theory the researcher approaches a situation without preconceptions, seeking others' experiences. Theory develops from the specific situation (Creswell, 2013). Grounded theory is typically used when existing theory is too abstract or absent (Creswell, 2013), such as in this study.

Here a survey asks qualitative and quantitative questions to elicit parental perspectives on leadership in children's media and co-viewing. The design assumes their responses prima facie valid. The researcher secured the survey site, facilitated the survey, and processed and analyzed the data, all within ethical guidelines.

Participants. Participants were parents of children age five to ten. This was the only criterion for taking the survey; no one was excluded for any other reason. The sample included thirty adults from central Maine, nineteen of whom meet weekly in a community program to discuss parenting skills and domestic issues. This target group was selected because its members fit the criterion and may perceive leadership in the media differently from other parents. All 
nineteen community program participants took the survey together. The researcher also selected eleven other participants, who fit the requirement: neighbors, extended family members, and work associates having no formal connections with each other. These participants took the survey individually.

Procedure. Before taking the survey, the participants read an overview of the research study, were asked if they had questions (which they did not), and signed their consent forms. The researcher then distributed the first half of the survey, the "Before Clip" Section (BCS), and paper for note taking. The "Before Clip" Section (BCS) contained fifteen questions: five demographic, three yes-or-no, two quantitative (Likert scale), and five open-ended. To preserve anonymity, the survey did not ask participants for any identifying personal information. Participants were asked to answer all the questions thoroughly and then to await further instructions. The researcher then collected the "Before Clip" Sections and placed them in a sealable manila envelope.

Then, the participants watched six short clips (with an average running time of forty seconds for each clip) from the movie Toy Story (Lasseter, 1995, 1999; Unkrich, 2010), each of which is an example of leadership described by Kouzes \& Posner (2002), McKee, Boyatzis, \& Johnston (2008), Avery (2004), and Heifetz (1994). Participants took a one-minute break between each of the six clips to reflect and to take notes.

After playing all six clips, the researcher administered the second "After Clip" Section (ACS) of the survey, which contained three yes-or-no and five open-ended questions. Participants used their notes and responded to these survey questions, thereby completing in about forty minutes the ACS and BCS sections of the survey. Each participant put their survey into the researcher's folder and then departed. The researcher then sealed the envelope that contained both the "Before Clip" and "After Clip" Sections and stored the envelope securely.

Data Analysis. Grounded theory was used to examine and to analyze the participants' surveys: organizing, classifying, interpreting, and making sense of the data (Creswell, 2013). On a spreadsheet demographic identifiers (sex, parent group membership, and educational level) were sorted, which were correlated with key survey terms. Inductive reasoning was used for most of the open-ended qualitative responses, which globally described how they perceive children learning from the media.

Assumptions and limitations. The researcher assumed that participants care what their children watch, seek to protect them from harm and wish to enhance their education. Parents presumably consider their children capable of receiving and understanding leadership lessons from the media. Lastly, parents presumably want to exploit social lessons from children's media.

The size of the participant group and its geographical limits (central Maine) obviously constrain generalizability. Partially answered questions reduce information for researchers. Finally, participants viewed only six clips of leadership within one narrative. Perhaps more programs would have provided deeper understanding. 


\section{Findings}

Sixteen women and fourteen men took the survey, the parents of sixty-five children (averaging 2.16 children per parent), thirty-one girls and thirty-four boys. Their average age was 6.23 years. Seventeen respondents indicated having a college degree (57\%), leaving thirteen without (43\%). Twenty-eight parents (93\%) had seen Toy Story before. Later we will examine how these demographic differences affected participant responses.

Before Clip questions. The Before Clip Section (BCS) asked parents if their child was learning from watching television and movies and why. Twenty-nine out of thirty (97\%) answered "yes." One parent commented, "Kids retain things they hear or see regardless if positive or negative." Another wrote, "Children incorporate what they see into their lives and use it as their basis of what they know." Other key words used in answers were: mimic, reiterate, incorporate, demonstrate, and model behavior. The one participant who answered "no," a male, not in the parenting group, without a degree, supported his answer by stating, "They don't watch enough TV to learn from it."

The second question, asking parents how often they watch TV / movies with their children (co-view), used a Likert scale with the following values: 1. Every time, 2. Usually, 3. Frequently, 4. Sometimes, 5. Occasionally, 6. Rarely, 7. Never. The mean score for all participants was 3 (frequently). Total answer frequency was: 1 (5), 2 (7), 3 (6), 4 (9), 5 (1), 6 (2) 7 (0) (see chart 1). The average score for parenting group members was 2.38; for non-group members, 3.91. Women averaged 2.56; men, 3.5. Lastly, participants with degrees averaged 3.13; those without, 3. Apparently, participants frequently co-view with their children, and parenting group members, women, and degree holders tend to view more than non-parenting group members, men, and people lacking a degree.

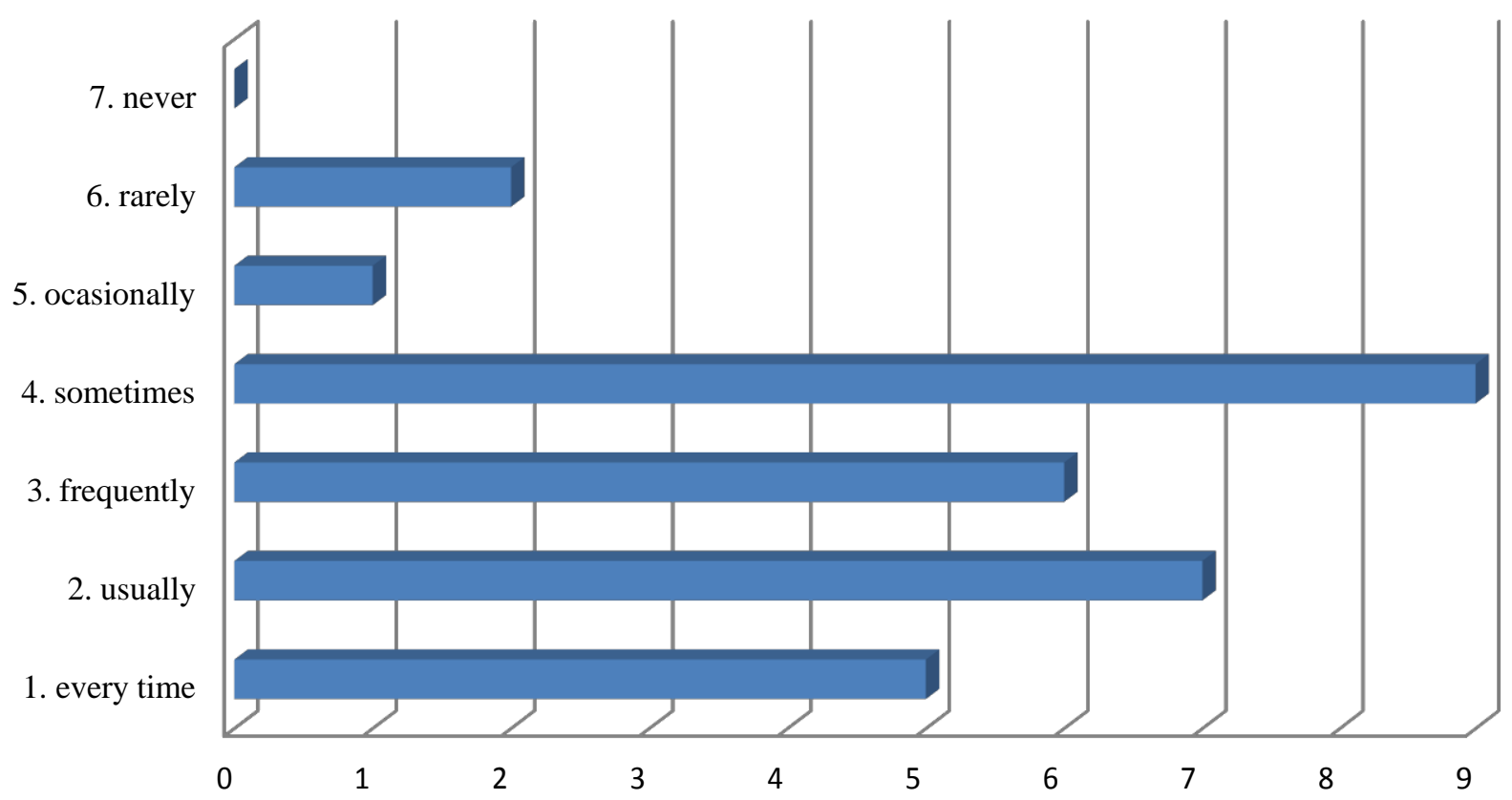

Figure 1 - Before-clip question two, frequency of co-viewing, all participants. 
The third question asked if participants reinforce messages presented in the program while co-viewing and if so, how. Twenty (67\%) said "yes," eighty-three percent of the parenting group compared to forty-two percent of non-group members. Eighty-one percent of females answered "yes," contrasting with fifty percent of males. Seventy-six percent of participants with degrees answered "yes" but only fifty-four percent of those without. When asked how, one person who answered affirmatively stated, "I connect the situations to life experiences she can identify so that she has an increased understanding." Another parent said, "I will comment on what is going on in the movie and how it may be important to behave in certain ways." One participant who answered "no" wrote, "We usually just watch together for fun with no talking about messages during movies" and "I don't think to reinforce. I just think of it as entertainment."

The fourth question asked participants how often they reinforce messages from the program after viewing. This question was a follow-up to number three and was only supposed to be answered by people who answered "yes" to the previous question, a direction that may not have been clear as twenty-nine of thirty participants answered this question regardless of how they answered question three. Although one participant did not answer the question, the mean score for participants was a 4. The total answer scale was: 1 (0), 2 (5), 3 (4), 4 (10), 5 (5), 6 (5) 7 (0) (see chart two). The average score for parenting group members was 3.82 while non-group members' average score was 4.33. Females averaged 3.68, and males, 4.46. Lastly, participants who held degrees had an average score of 3.65, while those without degrees scored 4.53.

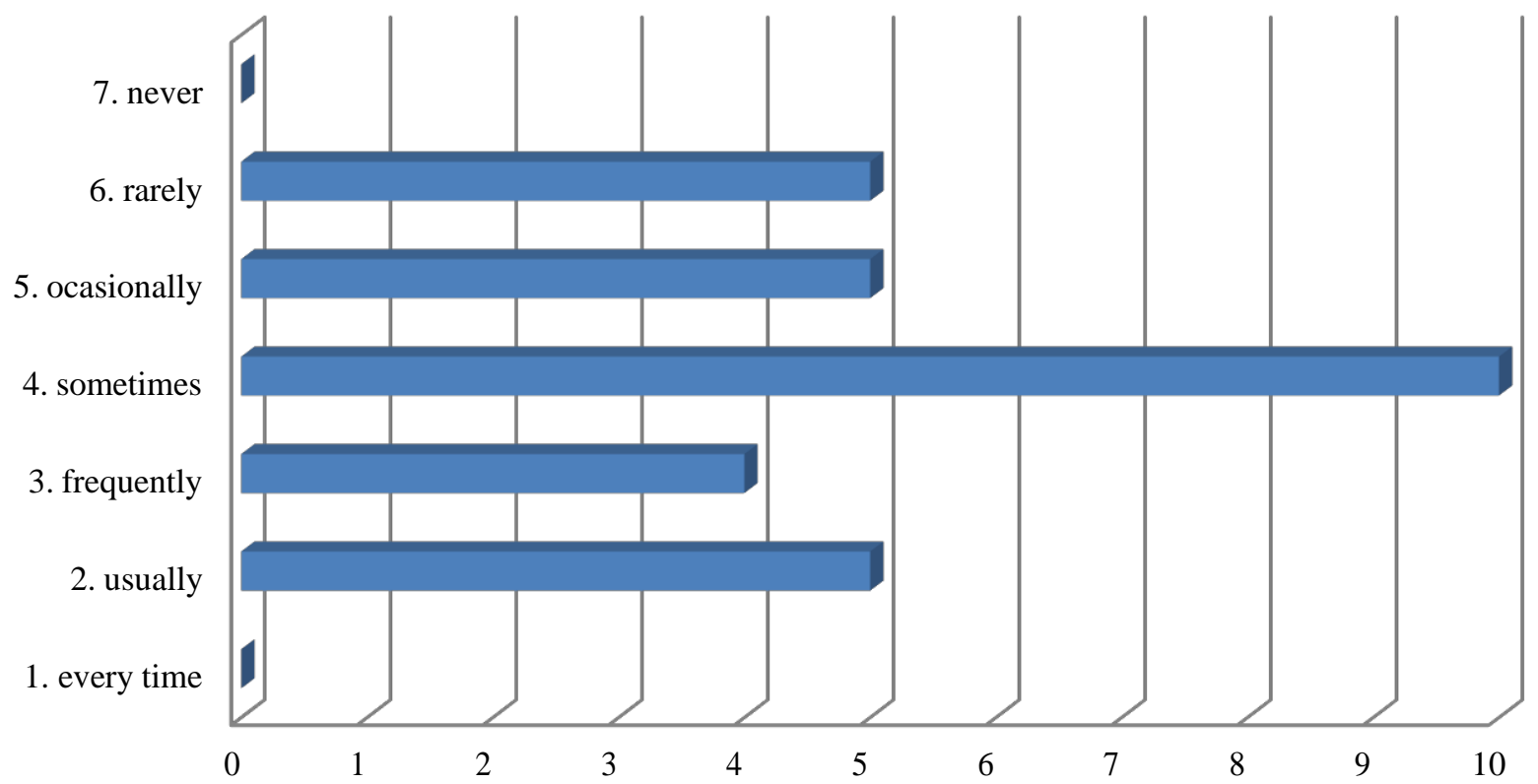

Figure 2 - Before -clip question four, message reinforcement frequency, all participants.

The fifth question asked parents to identify the most important attributes in a leader. The participants used one hundred and thirteen words or phrases to describe leadership. To discern attributes that participant's value, the data were divided into two categories: emotional and executional attributes of leadership. Emotional leadership attributes are expressive or 
relationship building behaviors. Words that fit this category are honest, trustworthy, compassionate, integrity, empathy, positive, generous, kind, confident, and courage. An executional leadership attribute is a perceived action or skill, as indicated in phrases such as "makes good decisions, leads by example, is organized, is competent, takes control, listens, communicates well, is experienced, is a risk taker, is helpful, is a problem solver, is educated, and gets things done." Of the one hundred and thirteen attributes listed, fifty-four (48\%) fell in the emotional category and fifty-nine (52\%) in the executional category. These nearly equal numbers show that participants recognize different aspects of leadership and value balance between them.

The sixth question asked parents if their child demonstrates leadership attributes and if so, which ones. Twenty-eight of thirty participants (93\%) said "yes." The two parents who said "no" were a male and a female not in the parenting group and not having a degree. Sixty-seven words or phrases described leadership for this question. Twenty-one behaviors (31\%) aligned with the emotional category (top three listed: integrity, compassion, confidence) and forty-six behaviors (69\%), with executional (top three listed: lead by example, communicates well, takes control). These data reveal fewer emotional than executional leadership behaviors recognized by the parents in their children. Either the children have not yet fully developed their emotional aptitude or parents do not recognize emotional behaviors as readily as executional ones in their children.

The seventh question asked participants if they teach their children about leadership and if so, what aspects. Twenty-one of thirty parents (70\%) said "yes." Sixty-seven percent of the parenting group members said they teach leadership, compared to seventy-five percent of nongroup members. Only on this question did participants not in the parenting group seem more favorably disposed to their children's leadership than people in the parenting group. No hypothesis yet explains why. Seventy-five percent of females answered "yes," contrasting with sixty-four percent of males. Seventy-six percent of participants with degrees answered "yes," compared to sixty-two percent of those without. When asked what aspects of leadership they teach, a participant who answered "yes" said, "Be open and accessible, listen, encourage others, have confidence, and be a lifelong learner." Other parents stated, "knowing when to lead, when to follow, when to speak up, when to be silent, when to listen" and "by setting examples and standing up for what I believe in." One parent who answered "no" to teaching leadership added, "I SHOULD be teaching leadership to my children but I don't know HOW to teach leadership." This honest answer reveals that many parents struggle to understand, incorporate, and reinforce leadership behavior with their children.

After Clip Section (ACS) questions. The first ACS question asked which leadership attributes/lessons, if any, parents recognized in the movie clips. All thirty participants described some, using 111 words or phrases. Only 36 descriptions (30\%) classed as emotional (top three: "positive, compassion, courage"), while 75 (70\%) were executional (top three: "teamwork, problem solving, taking charge").

The second question asked parents if/how they reinforce leadership lessons while or after co-viewing media with their children. Twenty-one parents (70\%) acknowledged doing so. Eighty-three percent of the parenting group members said that they reinforce leadership lessons 
compared to fifty percent of non-group members. Of females, seventy-five percent and of males, sixty-two percent answered "yes." Of participants with degrees, seventy-one percent answered "yes," compared to sixty-nine percent of those without. When asked how they reinforce lessons, a parent who answered "yes" said, "I talk to them about what the leader is doing in certain situations and highlight their behaviors." Another participant commented, "By discussing what made the characters actions or words positive or negative and how poor actions can change into positive ones."

The third question asked participants if/how reinforcing leadership lessons from the media benefits their child. Twenty-seven of 27 respondents (100\%) said "yes." Three participants did not respond (all male, parenting group members, without a degree). A parent who answered "yes" elaborated, "The movie can be a valuable teaching tool. You can reinforce what is taught which helps them make the connection." Another participant wrote, "Children need to understand leadership behaviors so they can be one" and "reinforcing gives kids an understanding of what leadership is."

\section{Discussion}

Compiled data revealed interesting differences between sub-groups. Parenting group members outscored non-group members on co-viewing frequency (BCS 2), message reinforcement (BCS 3), message reinforcement frequency (BCS 4), and reinforcing leadership lessons presented in media (ACS 2). Only on questions six and seven, about children demonstrating leadership and teaching children leadership, did non-member participants score higher, and this, by only one person per question (see chart 3). These findings suggest that the parenting class helps parents focus on co-viewing and reinforcing leadership messages from the media and generally increases their involvement with their children's media viewing and learning.

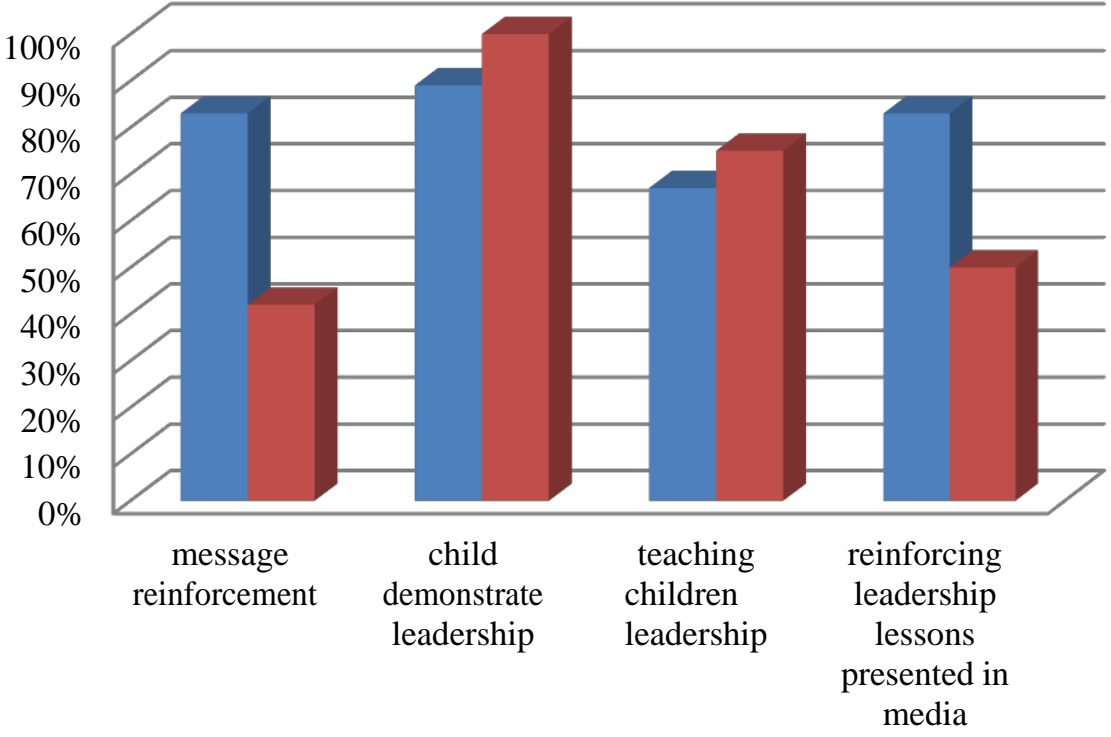

Figure 3 - Parenting group member vs. non- group member
- parenting group member non member 
Women and men compare similarly. Females scored more favorably on co-viewing frequency (BCS 2), message reinforcement (BCS 3), message reinforcement frequency (BCS 4), child demonstrate leadership (BCS 6), teaching children leadership (BCS 7), and reinforcing leadership lessons presented in media (ACS 2). Males did not score higher than females on any question (see Chart 4). These findings indicate that mothers play a larger role mediating their children's programming and reinforcing messages and suggest an opportunity or even a need for fathers to become more engaged.

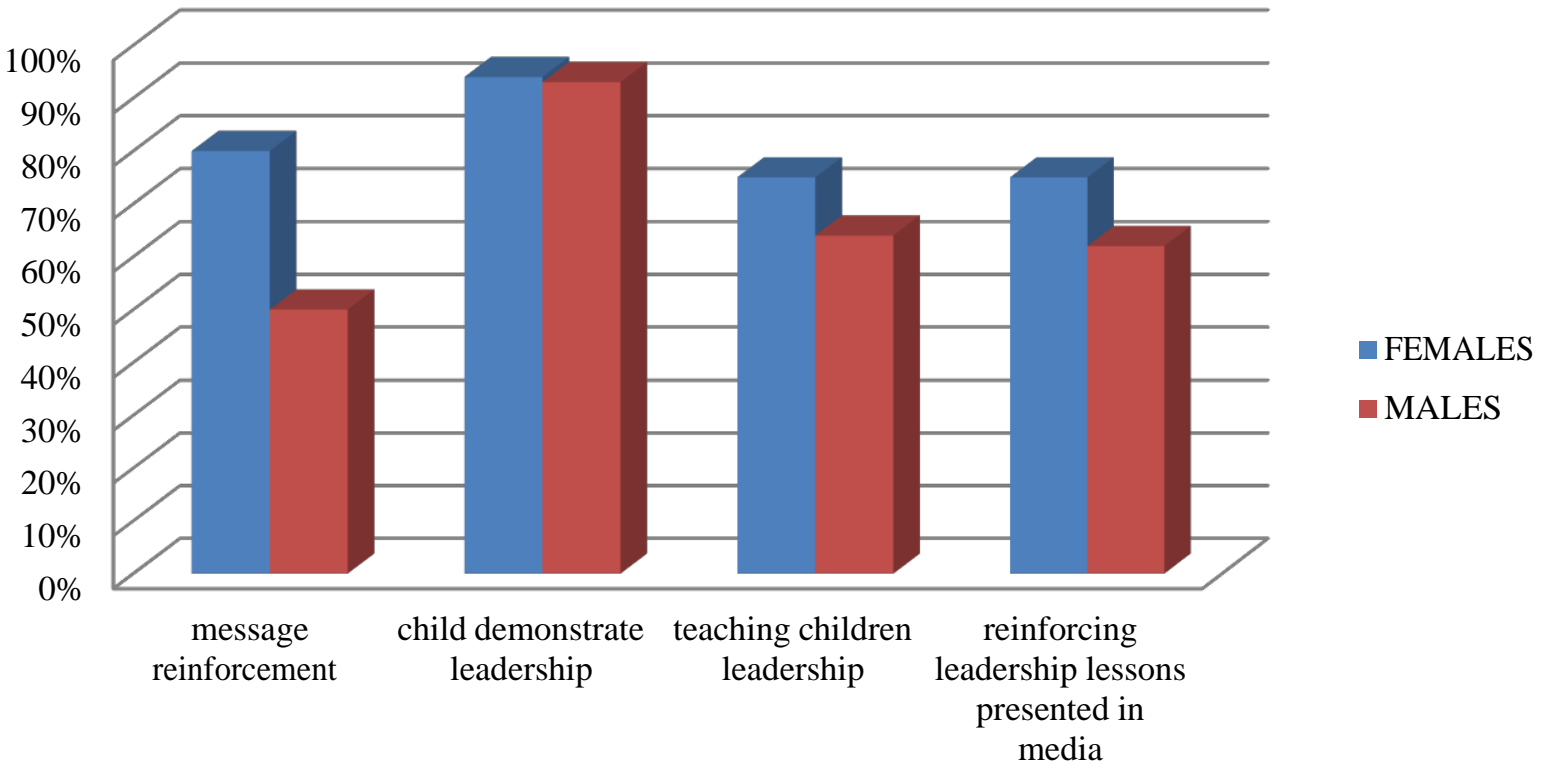

Figure 4 - Female vs. male.

Differences were also seen between participants with and without degrees. The former scored more favorably on message reinforcement (BCS 3), message reinforcement frequency (BCS 4), child demonstrate leadership (BCS 6), teaching children leadership (BCS 7), and reinforcing leadership lessons presented in media (ACS 2). The two groups tied for co-viewing frequency (BCS 2). Participants without degrees scored lower than parents with degrees on every question (see Chart 5). Apparently formal education makes parents aware of leadership in their children's media programs. 


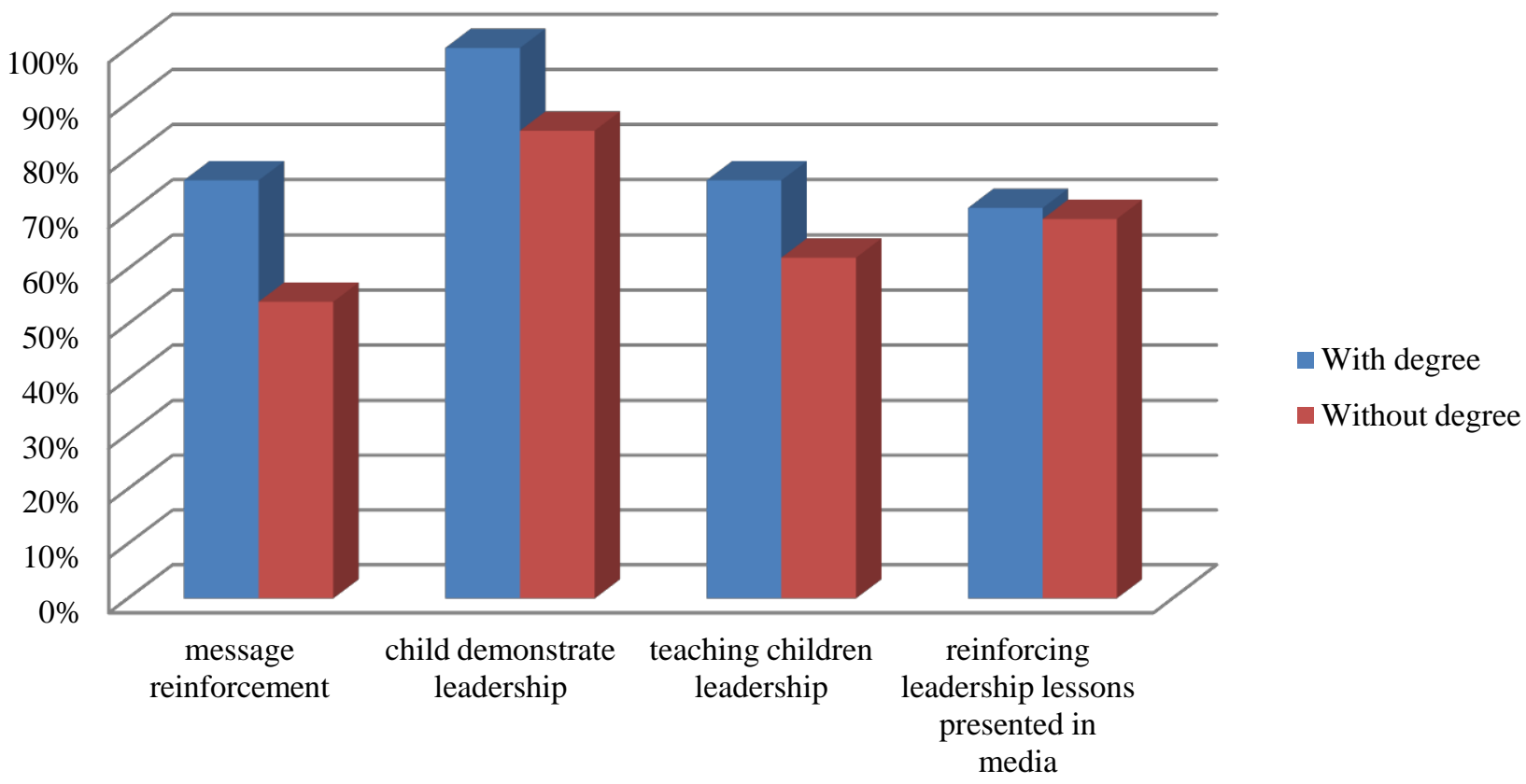

Figure 5 - Parents with a degree vs. parents without.

The penultimate question asked participants how to encourage parents to reinforce leadership lessons from the media. They recommended education. One parent suggested, "Education for the parents about the benefits of reinforcing leadership lessons." Another said, "Articles and pamphlets about leadership in children's media. TV commercials, public service announcements, and trainings would all be very helpful." Still another parent suggested an interactive DVD with features that highlight leadership in the movie and a game-play format for children to enhance the messages.

Lastly, the study asked participants for further thoughts. Among the seven responses one parent said that the study "got them thinking about why we should talk to our kids more after viewing TV/ movies with them." Another wrote, "Interesting perspective - never thought of it before." A third stated, "I think this is a fantastic way to educate parents to take steps towards helping their children become good leaders. I've never considered doing this and the movies and TV shows now appear to be a tool to me rather than just entertainment."

\section{Conclusion}

We learn about leadership (working with others to achieve a goal) throughout our lives, but perhaps most from five to ten years old, when peers, family members, and children's media influence us greatly. Age-appropriate content, television and movies can augment a child's development. Arguably children learn most from media when parents co-view programs with them and reinforce lessons presented. Dialogue about these lessons enables children to transfer them to other aspects of their life. Parents need to understand and to reinforce these messages to 
enhance their children's learning.

This study elucidated parents' feelings about children's media and leadership. Ninetyseven percent of participants agreed that children learn from the media; ninety-seven percent claimed that their child demonstrates leadership behavior. Of parents responding one hundred percent recognized leadership behaviors in the clips from Toy Story, and one hundred percent saw benefit in reinforcing leadership lessons presented in the media. Members of the parenting group, females, and degree holders scored higher on most questions than their counterparts, nonparenting group members, males, and parents lacking degrees. These findings argue for formal and informal education, for effective parental mediation, and that fathers can do more reinforcing of lessons from the media.

This research reveals a big gap between parents' thought and action. All participants agreed on the benefit of reinforcing leadership lessons in the media for their children. But only seventy percent of participants reported doing it. Analogously, everyone knows regular exercise keeps you healthy, but not everyone stays fit. How do we get more parents to reinforce the leadership messages presented in children's TV and movies?

We should start with education for parents. More educated participants scored higher than those less educated. Perhaps other local organizations like the parent group surveyed in this research can examine how the children's media affect their children, and how parents can reinforce leadership messages during or after co-viewing. Any group of adults can take a similar survey to introduce the topic of leadership in children's media. Once parents realize that media convey some positive messages, they can discuss leadership and related behavior with their children.

Producers of children's programs can also support parents' reinforcing leadership. If they understood the need for leadership and parents' desire to develop it in children, producers could assist parents teaching their children. They could produce DVDs that pause for parents to discuss certain scenes with their children. Such easy measures could earn parents' praise. Also questions inside a DVD case could help parents discuss leadership in the movie. These suggestions from participants could help parents reinforce leadership messages with their children while coviewing.

All children can develop leadership skills, and they have many opportunities. Media strongly influence today's children and we heartily recommend that parents use programs to teach rather than simply amuse their children. The leaders of tomorrow need to be taught, and how better than by viewing an entertaining program with your child and reinforcing its leadership messages? 


\section{References}

Alexander, A. (2009). Media and the family. In S. Calvert, \& B. Wilson, The handbook of children, media and development (p. 121). Chichester, U.K.: Blackwell Publishing Ltd.

Andrews, E. (2012). Developing Leadership Qualities In Your Child. Retrieved October 15, 2012, from Streetdirectory.com:

http://www.streetdirectory.com/travel_guide/15585/parenting/developing_leadership_qua lities_in_your_child.html

Avery, G. (2004). Understanding Leadership. Los Angeles: SAGE Publications.

Brungardt, C. (1997). The making of leaders: A review of research in leadership development and education. Journal of leadership and organizational studies, (3)3, 81-95.

Bryce, J., \& Leichter, H. (1983). The family and television: forms of mediation. Journal of Family Issues, (4), 309-328.

Calvert, L., \& Kotler, A. (2003). Lessons from children's television: The impact of the Children's Television Act on children's learning. Journal of Applied Development Psychology, 24(3) 275-335.

Calvert, S., \& Wilson, B. (2008). The handbook of children, media and development. Chichester, U.K.: Blackwell Publishing Ltd.

Crane, V., \& Chen, M. (2003). Content development of children's media. The faces of of televisual media: Teaching violence, selling to children.

Creswell, J. W. (2013). Qualitative inquiry \& research design. Thousand Oaks, California: SAGE Publications.

Davies, M. (1997). Fake, fact, and fantasy: children's intrepretations of television reality. New Jersey: Lawrence Erlbaum Associates, Inc.

Dorr, A., Kovaric, P., \& Doubleday, C. (1989). Parent-child coviewing of television. Journal of Broadcasting \& Electronic Media, 33(1), 15-51.

Feshbach, N., \& Feshbach, S. (1997). Children's empathy and the media: Realizing the potential of television. In S. Kirschner, \& D. Kirschner, Perspectives on psychology and the media. Washington D.C.: American Psychology Association.

Friedrich, L., \& Stein, A. (1973). Aggressive and social television programs and the natural behavior of preschool children. Monographs of the society for research in child development, 38(4, serial No. 151). 
Gaunlett, D. (1995). Moving experiences: Understanding television's influence and effects. London: John Libbey.

Heifetz, R. A. (1994). Leadership Without Easy Answers. Cambridge: The Belknap Press of Harvard University Press.

K.M. (2011, Octobber 3). Leadership Skills for Kids. Retrieved October 16, 2012, from Buzzle: http://www.buzzle.com/articles/leadership-skills-for-kids.html

Kirkorian, H., Wartella, E., \& Anderson, D. (2008). Media and Young Children's Learning. Future of Children, 18(1), 39-61.

Kirkpatrick, S., \& Locke, E. (1991). Leadership: Do traits matter? Academy of Management Executive, 5(2), 48-60.

Kouzes, J., \& Posner, B. (2002). The leadership challenge. San Francisco: Jossey-Bass.

Lasseter, J. (Director). (1995). Toy Stoy [Motion Picture].

Lasseter, J. (Director). (1999). Toy story 2 [Motion Picture].

Leedy, P., \& Ormrod, J. (2013). Practical Research planning and design. Boston: Pearson.

Loh, A. (2012). Developing Leadership Skills in Children. Retrieved October 15, 2012, from Brainy-Child: http://www.brainy-child.com/article/developing-leadership-skills.shtml

Mar, R., Tackett, J., \& Moore, C. (2010). Exposure to media and theory-of-mind development in preschoolers. Cognitive Development, 25, 69-78.

Mawson, B. (2008). Gender and leadership styles in children's play. Auckland, New Zealand.

McKee, A., Boyatzis, R., \& Johnston, F. (2008). Becoming a Resonant Leader. Boston: Harvard Business Press.

McMahon, T. B. (2004). Using entertainment media to inform student affairs teaching and practice to related leadership. New Directions for Student Services,(108), 61-70.

Nelson, A. E. (2010). Stepping in early to grow great leaders. Leadership in Action, 29(6), 20-24.

Riggio, R. (2011). Cutting-Edge leadership. Retrieved October 15, 2012, from Psychology Today: http://www.psychologytoday.com/blog/cutting-edge-leadership/201106/5leadership-and-life-lessons-you-learn-your-kids

Stogdil, R. (1948). Personal factors associated with leadership. The Journal of Psychology: Interdisciplinary and Applied, 25, 35-71. 
Swan, K. (2011). Raising Tomorrow's Leaders: 6 Skills to Teach Your Children . Retrieved October 15, 2012, from A Successful Woman:

http://www.asuccessfulwoman.com/aswstory/raising-tomorrows-leaders-6-skills-teachyour-children

Unkrich, L. (Director). (2010). Toy Story 3 [Motion Picture].

Valkenburg, M., Krcmar, M., \& de Roos, S. (1998). The impact of a cultural children's program and adult mediation on children's knowledge and attitudes towards opera. Journal of Broadcasting and Electronic Media, 42, 315-26.

Walling, J. (1976). The effect of parental interaction on learning from television. Communication Education, 25(1), 16-24.

Wartella, E., \& Robb, M. (2008). Historical and recurring concerns about children's use of the mass media. In S. Calvert, \& B. Wilson, The handbook of children, media and development (p. 18). Chichester, U.K.: Blackwell Publishing Ltd.

\section{Author Biographies}

Elizabeth Fisher Turesky is an Associate Professor of Leadership and Organizational Studies at the University of Southern Maine, where she teaches graduate and undergraduate courses in Leadership, Leadership Study Abroad, Organizational Change and Development, Organizational Behavior, Group Dynamics and Training and Development. She is the recipient of the University of Southern Maine Faculty Senate Awards for Service and Research and Maine Campus Compact's Donald Harward Faculty Award for Service-Learning Excellence. She has published in such journals as the Organizational Management Journal, Academic Leadership Journal, Journal of Leadership Education, The Coaching Psychologist and Career and Adult Development Journal. She has led organizational change efforts, conducted workshops and presented nationally and internationally at conferences on Change Leadership, Team Development, Conflict Management, Learning and Teaching Styles, Creative Pedagogy and Women and Leadership. Her teaching and scholarship are rooted in experiential learning principals with an abiding commitment to create inclusive, nurturing learning environments. Her scholarship focuses on leadership, Organizational Change and the nexus of experiential learning and leadership development. She holds a masters degree in Public Administration from the University of Colorado, a doctorate from Case Western Reserve University's Department of Organizational Behavior (the Weatherhead School of Management) and is a member of the National Training Laboratory Institute of Applied Behavioral Science (NTL), the International Leadership Association, the Academy of Management and the Organizational Behavior Teaching Society. 
Lee Morin graduated from the University of Southern Maine in 2013 with a Master of Arts in Leadership Studies and is a member of the Golden Key Honor Society for academic excellence. Lee selected the leadership program because of its importance to his organizations and leadership can be utilized in all facets of life. Professionally, Lee is a Sales District Leader for the Pepsi Beverages Company in Auburn, Maine and has been employed there for eleven years. He is actively involved in his workplace, leading the Culture and Inclusion Committee at Pepsi, which brings work groups together to strive to be the "Best Place to Work." Lee leads community involvement programs, employee appreciation week, and several other significant special events. Lee has been recognized by his employer on several occasions for his leadership including the Role Model Award for breaking down barriers between work group (2009), The Gorilla Award for great leadership in a tough economic environment (2010), and the True Blue Award for willingness to expand strategic responsibilities and creatively implementing them (2011). Lee enjoys coaching youth sports and lives in Auburn, Maine with his wife Jenny and his children, Dexter and Marissa, both age seven.

Betty Robinson, Ph.D. in Sociology from Boston University, came to USM's LewistonAuburn College (LAC) in 1988 to co-found both the College and what became the Leadership and Organizational Studies program in 1996. Also in 1996, she became Dean of the College serving for seven years, before returning to faculty in 2003 to teach in the undergraduate and newly established masters' programs in Leadership Studies. Within her field, Dr. Robinson focuses on the integration of the concepts of social capital and cultural competence in leadership studies, as well as on new thinking about what leadership can mean for the 21st century and our shrinking globe. Believing that practice is as essential as theory, Dr. Robinson has served and continues to serve on a number of community and statewide non-profit boards, often in officer positions. She has been an active member of the International Leadership Association and coauthored their Guidelines for Leadership Education Programs. Although now holding Emeritus status, she remains active in the development of leadership in diverse, low-income youth. 